\title{
ESTUDO SOBRE A CÓPULA INTERESPECIFICA ENTRE MOLUSCOS PLANORBIDEOS BIOMPHALARIA GLABRATA E B. TENAGOPHILA
}

\author{
Luiz A. MAGALHĀES * \\ José $F$. de CARVALHO ** \\ Urara KAWAZOE*
}

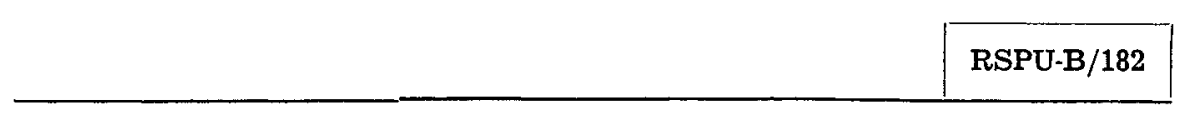

Magalhães, L. A. et al. - Estudo sobre a cópula interespecifica entre moluscos planorbideos Biomphalaria glabrata $e$ B. tenagophila. Rev. Rev. Saúde públ., S. Paulo, 7: 299-301, 1973.

Resumo: Foi estuãada a frequiência da cópula interespecifica entre espécimes de Biomphalaria glabrata $e \mathrm{~B}$. tenagophila. Os resultados da experiência levaram a conclusão de que há preferência pela cópula intraespecifica, ocorrendo, contudo, cópulas interespecificas.

Unitermos: Planorbidae *; Biomphalaria *.

Paraense 2 (1955) estudando a reprodução em Biomphalaria glabrata verificou que esses moluscos são capazes de se autofecundarem quando isolados individualmente. Se colocados reunidos com outros moluscos da mesma espécie, prontamente cessam o processo de autofecundação e iniciam a reprodução cruzada.

Paraense \& Deslandes 3 (1955), em estudo sobre o isolamento reprodutivo entre B. glabrata e B. tenagophila, demonstraram que o isolamento observado não é de natureza etológica, tendo os autores observado frequientemente " corte interespecifica".
Procuramos no presente trabalho verificar se há ou não predileção para cópula intraespecífica em moluscos colocados frente a exemplar de espécie diferente. Morfologicamente $B$. glabrata e $B$. tenagophila são extremamente semelhantes, fazendo-se distinção das espécies pela presença ou não de uma crista renal (Paraense \& Deslandes 4, 1959) sendo que seus aparelhos reprodutores são aparentemente idênticos.

\section{MATERIAL E METODOS}

Utilizamos B. glabrata de Belo Horizonte, Minas Gerais e $B$. tenagophila de São José dos Campos, São Paulo.

* Do Instituto de Blologia da Universidade Estadual de Campinas. - Caixa Postal 1170 Campinas, S.P. - Brasil.

* Do Instituto de Ciências Matematicas de São Carlos. Universidade de Sáo Paulo. São Carlos, S.P. - Brasil. 
MAGALHAES, L. A. et al. - Estudo sobre a cópula interespecifica entre moluscos planorbideos Biomphalaria glabrata e B. tenagophila. Rev. Saúde públ., S. Paulo, 7:299-301, 1973.

Em 20 frascos (Grupo I) foram colocados 4 caramujos por frasco, sendo 2 B. glabrata e 2 B. tenagophila. Os caramujos escolhidos mediam aproximadamente $15 \mathrm{~mm}$ de diâmetro máximo e os exemplares de $B$. tenagophila apresentavam bem visível ao ponto de tornar-se fácil sua distinção a simples observação direta.

Durante 40 dias foram feitas quatro anotações diárias a fim de se verificar quantos moluscos copulavam no momento da observação e se as cópulas eram inter ou intraespecíficas. As observações foram realizadas durante o período diurno.

Em outros 20 frascos (Grupo II) foi depositado um par de $B$. glabrata por frasco e durante 40 dias anotaram-se $O$ número de desovas, os ovos estéreis, os inviáveis e o total de ovos viáveis.

O mesmo procedimento foi feito com B. tenagophila (Frascos do Grupo III).

Consideramos como desovas estéreis as que não continham embriões na ocasião da oviposição e de inviáveis as que tinham sua evolução interrompida.

Durante a experiência os moulscos foram alimentados com retângulos de alface e a água dos frascos era renovada duas vezes por semana.

A experiência foi realizada durante os meses de Agosto e Setembro.

$$
\text { RE S U L T A D O S }
$$

Os resultados estão condensados nas Tabelas 1 e 2.

T A B E L A 1

Número de cópulas observadas durante o periodo da experiência (Grupo I)

\begin{tabular}{l|c} 
Espécies participantes & N.o de cópulas \\
\hline B. glabrata $x$ B. glabrata & 96 \\
B. tenagophila $x$ B. tenagophila & 93 \\
B. glabrata $x$ B. tenagophila & 110 \\
\hline
\end{tabular}

T A B E L A 2

Oviposiçóes observadas nos três grupos de 20 frascos

\begin{tabular}{|c|c|c|c|c|c|}
\hline Tipo & $\begin{array}{l}\text { N. total } \\
\text { de } \\
\text { moluscos }\end{array}$ & $\begin{array}{c}\text { Total de } \\
\text { ovos }\end{array}$ & $\begin{array}{l}\text { Esté. } \\
\text { reis }\end{array}$ & $\begin{array}{c}\text { Inviá- } \\
\text { veis }\end{array}$ & Viáveis \\
\hline \multicolumn{6}{|l|}{ Grupo I } \\
\hline (B. glabrata $\times$ B. tenagophila) & 80 & 4.516 & 691 & 291 & 3.534 \\
\hline \multicolumn{6}{|l|}{ Grupo II } \\
\hline (B. glabrata $\times$ B. glabrata) & 40 & 2.132 & 4 & 4 & 2.124 \\
\hline (B. tenagophila $\times B$. tenagophila) & 40 & 1.481 & 1 & 4 & 1.416 \\
\hline
\end{tabular}


MAGALHĂES, L. A. et al. - Estudo sobre a cópula interespecífica entre moluscos planorbídeos Biomphalaria glabrata e B. tenagophila. Rev. Saúde públ., S. Paulo, 7:299-301, 1973.

\section{DISCUSSÃO E CONCLUSÃO}

Como é relatada a competição interespecifica entre as espécies estudadas MAGALhães 1, 1966) poderíamos pensar que no processo competitivo participasse como fator influente a cópula interespecífica, originando desovas estéreis e inviáveis.

Caso não houvesse predileção no acasalamento, na presente experiência, deveríamos esperar frequiências da seguinte grandeza quanto ao número de cópulas:

B. glabrata $\times$ B. glabrata

B. tenagophila $\times$ B. tenagophila

B. glabrata $\times$ B. tenagophila
Verificamos estatisticamente esta hipótese com os dados observados (Tabela 1), a qual foi rejeitada ao nível de $5 \%$. Logo, preferimos supor que, embora possivel a cópula interespecífica, os caramujos possuem mecanismo que thes fornecem preferência pela cópula intraespecífica.

Com respeito à viabilidade das desovas, através dos testes baseados na distrituição qui-quadrado, concluimos que há diminuição da viabilidade dos ovos, quando ocorre a cópula interespecífica.

Desta forma, é lícito supor que a cópula interespecífica aja como um dos fatores que intervem na competição biológica entre as duas espécies estudadas.

RSPU-B/182

MAGALHÃES, L. A. et al. - [Inter-specific mating between planorbid snails Biomphalaria glabrata and B. tenagophila.] Rev. Saúde públ., S. Paulo, 7: $299-301,1973$.

Summary: An experiment on the inter-specific mating of $\mathbf{B}$. glabrata and $B$. tenagophila snails was related. The results led to conclude that the snails prefer intra-specific mates, even though inter-specific ones occur.

Uniterms: Planorbidae *; Biomphalaria *.

\section{REFERENCIAS BIBLIOGRÁFICAS}

1 - MAgalhäS, L. A. - Estudo de uma população de Biomphalaria glabrata (Say, 1818), recentemente introduzida no estado da Guanabara. Folia clin. biol., S. Paulo, 35:102-20, 1966.

2 - PARAENSE, W. L. - Autofecundação cruzada em Australorbis glabratus. Mem. Inst. Oswaldo Cruz, 53:227-91, 1955.
3 - PARAense, W. L. \& DEslandes, N. Isolamento reprodutivo entre Australorbis glabratus e A. nigricans. Mem. Inst. Oswaldo Cruz, 55:321-7, 1955.

4 - PARAense, W. L. \& DESLANDES, N. The renal ridge is a reliable charactes for separating Taphius glabratus from Taphius tenagophilus. Amer. J. trop.Med. Hyg., $8: 456-72,1959$. 